\title{
Nonlinear Analysis of Concrete Beams Strengthened with FRP Plate
}

\author{
Jia Yang ${ }^{12, \text { a }}$ \\ ${ }^{1}$ College of Architectural and Civil Engineering, Shenyang University, Shenyang, China \\ ${ }^{2}$ The Key Laboratory of GeoenvironMental Engineering, Liaoning, China \\ ayangjia0918@163.com
}

Keywords: FRP plate; Reinforced concrete; Nonlinear Analysis

Abstract. FRP plates can be bonded to the surface of concrete beam through the structural adhesive. Then the FRP plate, concrete beam and adhesive layer work together. Based on the assumption of plane section remaining, non-slip on interface and stress-strain relationships of materials, the calculating program is proposed, and the nonlinear analysis mode of concrete beams strengthened with FRP plate is researched. The relationships between moment and curvature, also between load and deformation of concrete beams strengthened with FRP plate are obtained. The results show that the moment-curvature curve and load-deformation curve of concrete beams strengthened with FRP plate can be separated to elastic stage, elastic-plastic stage and plastic stage.

\section{Introduction}

Fiber reinforced plastic (FRP) plate have many advantages of lightweight and high strength, corrosion resistance, anti-fatigue and so on. Since the appearance of FRP, it is widely concerned and valued from engineering circles. External bonding of FRP composites has become a popular technique for strengthening RC beams all over the world. FRP plates can be bonded to the surface of $\mathrm{RC}$ beam. With the increasingly extensive application in actual engineering, its theoretical research has brought high attention. At present, many experts and scholars have carried out many experimental research and theoretical analysis about it ${ }^{[1-8]}$. To have a further understanding about the mechanical properties on the theory and provide a more reliable theoretical basis for the application of the design formulas, the numerical method should be used. The full-range nonlinear analysis from loading to failure of concrete beams strengthened with FRP plate is very necessary.

\section{Material Constitutive Model}

The stress-strain relations of concrete

The Hognestad model is used as the concrete constitutive model, and the stress-strain curve is divided into four parts. The stress-strain relations of concrete are respectively as given below.

$$
\begin{cases}\sigma_{c}=f_{c}\left[2 \frac{\varepsilon_{c}}{\varepsilon_{0}}-\left(\frac{\varepsilon_{c}}{\varepsilon_{0}}\right)^{2}\right] & \left(0<\varepsilon_{c} \leq \varepsilon_{0}\right) \\ \sigma_{c}=f_{c}\left[1-0.15\left(\frac{\varepsilon_{c}-\varepsilon_{0}}{\varepsilon_{u}-\varepsilon_{0}}\right)\right] & \left(\varepsilon_{0} \leq \varepsilon_{c} \leq \varepsilon_{u}\right) \\ \sigma_{c}=\frac{2 \varepsilon_{c}}{\varepsilon_{c}+\varepsilon_{t 0}} f_{c t} & \left(\varepsilon_{t 0} \leq \varepsilon_{c}<0\right) \\ \sigma_{c}=f_{c t} & \left(\varepsilon_{t 0} \leq \varepsilon_{c} \leq \varepsilon_{t u}\right)\end{cases}
$$

Where, $\varepsilon_{t u}, \varepsilon_{t 0}$ are respectively the tensile ultimate strain of concrete and the tensile elastic ultimate strain; $\varepsilon_{c u}, \varepsilon_{0}$ are respectively the compression ultimate strain of concrete and the peak strain of concrete; $f_{c t}$ is the tensile strength of concrete; $f_{c}$ is the compression strength of concrete. 


\section{The stress-strain relations of steel bars}

It is assumed that the steel bar is a kind of ideal elastic and plastic material, also considered the post-yield strain hardening. The equations are respectively as given below.

$$
\begin{cases}\sigma_{s}=-f_{y}+E_{s}^{\prime}\left(\varepsilon_{s}-\varepsilon_{s h}\right) & \left(-\varepsilon_{s u}<\varepsilon_{s}<-\varepsilon_{s h}\right) \\ \sigma_{s}=-f_{y} & \left(-\varepsilon_{s h}<\varepsilon_{s} \leq-\varepsilon_{y}\right) \\ \sigma_{s}=E_{s} \varepsilon_{s} & \left(-\varepsilon_{y} \leq \varepsilon_{s} \leq \varepsilon_{y}\right) \\ \sigma_{s}=f_{y} & \left(\varepsilon_{y}<\varepsilon_{s} \leq \varepsilon_{s h}\right) \\ \sigma_{s}=f_{y}+E_{s}^{\prime}\left(\varepsilon_{s}-\varepsilon_{s h}\right) & \left(\varepsilon_{s h}<\varepsilon_{s}<\varepsilon_{s u}\right)\end{cases}
$$

\section{The stress-strain relations of FRP}

The stress-strain relation of FRP is linear elastic. The equation of stress-strain relations is as given below.

$$
\sigma_{f}=E_{f} \varepsilon_{f} \quad\left(0<\varepsilon_{f} \leq \varepsilon_{f u}\right)
$$

Where, $E_{f}$ is elastic modulus of FRP; $\varepsilon_{f u}$ is ultimate tensile strain of FRP.

\section{Analysis Method}

\section{Calculation Model}

According to the mechanical characteristics of the concrete beams reinforced with FRP plate, during the analysis process, the basic assumptions are as follows:

1. Section complies with the plane section assumption.

2. Ignoring the influence of the slip effect.

3. Element stress is uniformly distributed.

4. Ignoring the time-dependent effect.

The concrete beam should be divided into finite strip. The FRP plate and steel bars should be treated according to the independent part. Assume that the stress of each strip is uniformly distributed and strain distribution of the section is linear distribution along the height of the section, which is shown in Fig.1.

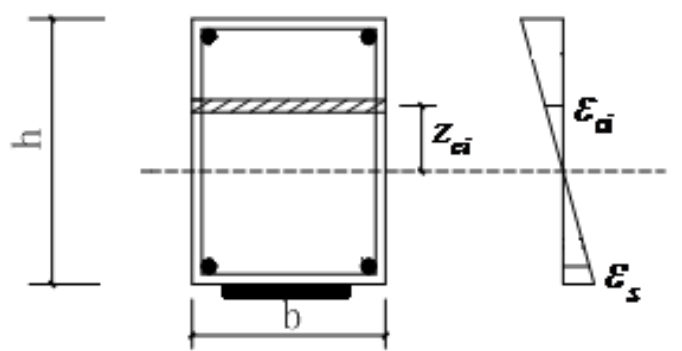

Fig.1 Strain distribution of the section

Assume that the strain of section at the centroid is $\varepsilon_{e}$, so the formula of the strain of the concrete and steel bars is as given below.

$$
\varepsilon_{i}=\varepsilon_{e}+z_{i} \varphi_{i}
$$

where, $\varepsilon_{i}$ is the strain of the i unit; $z_{i}$ is the distance from the i stripe to the height of half section $\frac{h}{2}$;

$\varphi_{i}$ is curvature of the section of the i stripe; $\varepsilon_{e}$ is the stain of section of the height of half section $\frac{h}{2}$. 
According to the stress-strain relations of concrete beam equilibrium condition, the force of each stripe of the section can be obtained, so the internal force of the total section is definite by the equation as follows.

$$
\begin{aligned}
& N=\sum_{i=1}^{m} A_{c i} \sigma_{c i}+A_{s} \sigma_{s}+\sigma_{f} A_{f} \\
& M=\sum_{i=1}^{m} A_{c i} \sigma_{c i} y_{c i}+A_{s} \sigma_{s} y_{s}+\sigma_{f} A_{f} y_{f}
\end{aligned}
$$

Where, $A_{c i}, A_{s}, A_{f}$ are the area of the unit of concrete, steel bars and FRP plate respectively; $\sigma_{c i}, \sigma_{s}, \sigma_{f}$ are the stress of the unit of concrete, steel bars and FRP plate respectively; $y_{c i}, y_{s}, y_{f}$ are the distance from the i stripe of concrete, steel bars, FRP plate of the beam to the centroidal axis of concrete beam respectively; $m$ is the unit number of the concrete.

\section{Calculation Principle}

An inter-relationship exists between moment and curvature, also between load and deformation of the concrete beams reinforced with FRP plate. After obtaining the curvature of each section of the component, the deformation of an arbitrary point of the component can be obtained by using integration method. If the component is divided into " $\mathrm{m}$ " segments, which means the component has " $\mathrm{m}+1$ " nodes, then the rotation and deformation of arbitrary cross-section can be obtained by this way.

The calculation steps are as follows:

1. Take the curvature as $\varphi=\varphi+\Delta \varphi$.

2. The strain of the centroid of concrete section is assumed as $\varepsilon_{c}$.

3. To compute the strain of stripe unit of concrete, steel bars and FRP plate.

4. To compute the stresses which is corresponding to the strain relationship of concrete, steel bars and FRP plate.

5. Add up the internal force which is obtained by the upper formulas to test whether it meets the equilibrium condition.

6. If it doesn't meet the equilibrium condition, the value of strain $\varepsilon_{c}$ needs to be adjusted. Then repeat the step $3 \sim 5$.

7. After meeting the equilibrium condition, internal force bending moment can be computed by the formulas. Accordingly, the moment $M$ which is corresponding to the curvature $\varphi$ would be obtained.

8. Cycle the step $1 \sim 7$ until the total $M-\varphi$ relationship is obtained.

\section{Calculation results}

\section{Calculation analysis of the relationship between moment and curvature}

Using the calculation program, the relationship between moment and curvature of concrete beams strengthened with FRP plate could be obtained, which is shown in Fig.2.

It can be seen from Fig.2, the moment-curvature curve of concrete beams strengthened with FRP plate can be divided into three stages. The first stage, moment varies linearly with curvature and the whole beam is in the elastic stage. The second stage, as the load increases, the growth rate of moment is relatively slower than the growth rate of curvature. In this stage, the steel bars begin to yield and the yielding range is under continuously development, and this is elastic-plastic stage. The third stage, when the moment exceeds the ultimate moment, plastic hinge appears on the local beam. The curve shows a trend that the constant moment and the increasing curvature, so this is plastic stage. Subsequently, the curvature continues to increase until the breaking happens to the whole concrete beam. 


\section{Calculation analysis of the relationship between load and deformation}

Using the calculation program, the relationship between load and deformation of concrete beams strengthened with FRP plate could be obtained, which is shown in Fig.3.

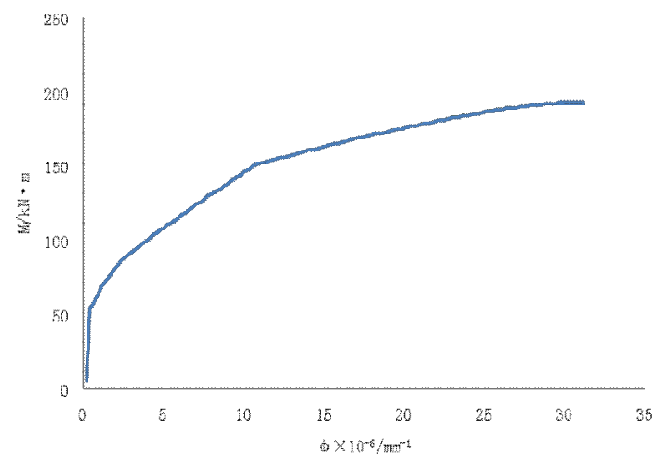

Fig. 2 The relationship between moment and curvature

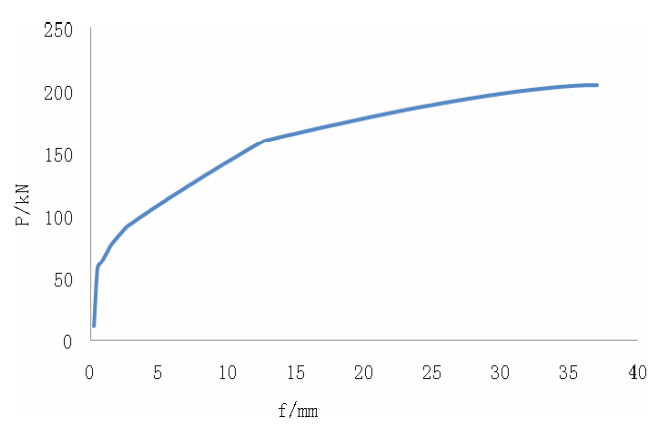

Fig.3 The relationship between load and deformation

It can be seen from Fig.3, the load-deformation curve of concrete beams strengthened with FRP plate can be divided into elastic stage, elastic-plastic stage and plastic stage. In elastic stage, deformation varies linearly with load and the whole beam is in the elastic stage. In the elastic-plastic stage, as the load increases, the growth rate of load is relatively slower than the growth rate of deformation, and load - deformation curve starts to deviate from linear relation. When the load exceeds the ultimate load, plastic hinge appears on the local beam. The curve shows a trend that the constant load and the increasing deformation, so this is plastic stage. Subsequently, the deformation continues to increase until the breaking happens to the whole concrete beam.

\section{Conclusion}

Using the method of exerting deformation by grading, the calculation results of moment-curvature and load-deformation of concrete beams strengthened with FRP plate are obtained. From the curve, it shows that the moment-curvature curve and load-deformation curve of concrete beams strengthened with FRP plate can be separated to three stages. They are respectively elastic stage, elastic-plastic stage and plastic stage. The nonlinear analysis mode of concrete beams strengthened with FRP plate is rational in theory, but the applicability of the program needs more experiments to verify.

\section{References}

[1] Lianguang Wang. Prestressed Composite Structures of Steel and Concrete. Beijing Science Press (2009) in press. (In Chinese)

[2] Bilal M A,Young G. S.Prestressed composite girders under positive moment.Journal of Structural Engineering, 1990,116(11)

[3] Toutanji H, Saafi M. Flexural behavior of concrete beams reinforced with glass fiber reinforced polymer (FRP) bars .ASCE Struct J, 2000, 97 (5)

[4] Burke C R,Charles W Dolan. Flexural design of prestressed concrete beams using frp tendons .PCI Journal, 2001, 46 (2)

[5] Carin L,Wollmann R. Strength and performance of fiber-reinforced concrete composite slabs .Journal ofStructural Engineering, 2004, 30 (3)

[6] Andrea D A,Luigino D.Nonlinear behavior of externally prestressed composite beams : Analytical model.Journal of Structural Engineering,1998, 124(5)

[7] Chi-ling pan, Wei-wen yu. Yield moment of cold-formed steel beams under different stain rates. Journal of Structural Engineering, 2001, 127(3): 264 270 
[8] Ahmad Ali Ghosn. Deflection of nested cold-formed steel Z-section. Journal of Structural Engineering, 2002, 128(11): 1422-1428 